\title{
Intercostal Retractions
}

National Cancer Institute

\section{Source}

National Cancer Institute. Intercostal Retractions. NCI Thesaurus. Code C87087.

The marked inward movement of the muscles between the ribs during inhalation, indicating that there is reduced pressure in the thoracic cavity, and which can be a sign of breathing difficulties. 